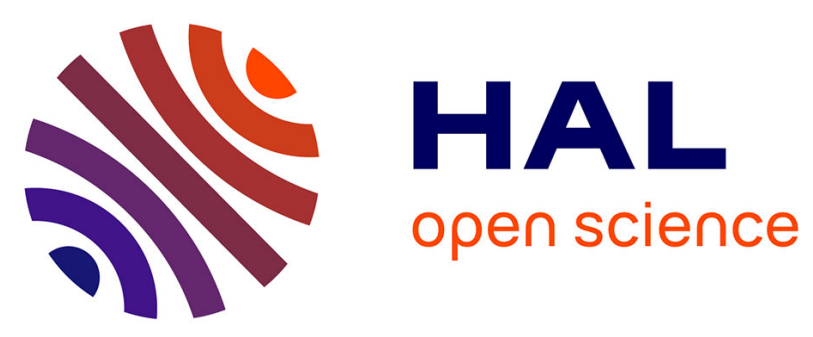

\title{
Qualitative study of supramolecular assemblies of $\beta$-cyclodextrin and cholecalciferol and the cobalt (II), copper (II) and zinc (II) ions
}

Ana Lucia Ramalho Mercê, Jaqueline Nicolini, Mustayeen A Khan, Gilles Bouet

\section{To cite this version:}

Ana Lucia Ramalho Mercê, Jaqueline Nicolini, Mustayeen A Khan, Gilles Bouet. Qualitative study of supramolecular assemblies of $\beta$-cyclodextrin and cholecalciferol and the cobalt (II), copper (II) and zinc (II) ions. Carbohydrate Polymers, 2009, 77 (2), pp.402-409. 10.1016/j.carbpol.2009.01.019 . hal-03249014

\section{HAL Id: hal-03249014 \\ https://univ-angers.hal.science/hal-03249014}

Submitted on 3 Jun 2021

HAL is a multi-disciplinary open access archive for the deposit and dissemination of scientific research documents, whether they are published or not. The documents may come from teaching and research institutions in France or abroad, or from public or private research centers.
L'archive ouverte pluridisciplinaire HAL, est destinée au dépôt et à la diffusion de documents scientifiques de niveau recherche, publiés ou non, émanant des établissements d'enseignement et de recherche français ou étrangers, des laboratoires publics ou privés.

\section{(2)(1) $\$$}

Distributed under a Creative Commons Attribution - NonCommercial - ShareAlikel 4.0 
Provided for non-commercial research and education use. Not for reproduction, distribution or commercial use.

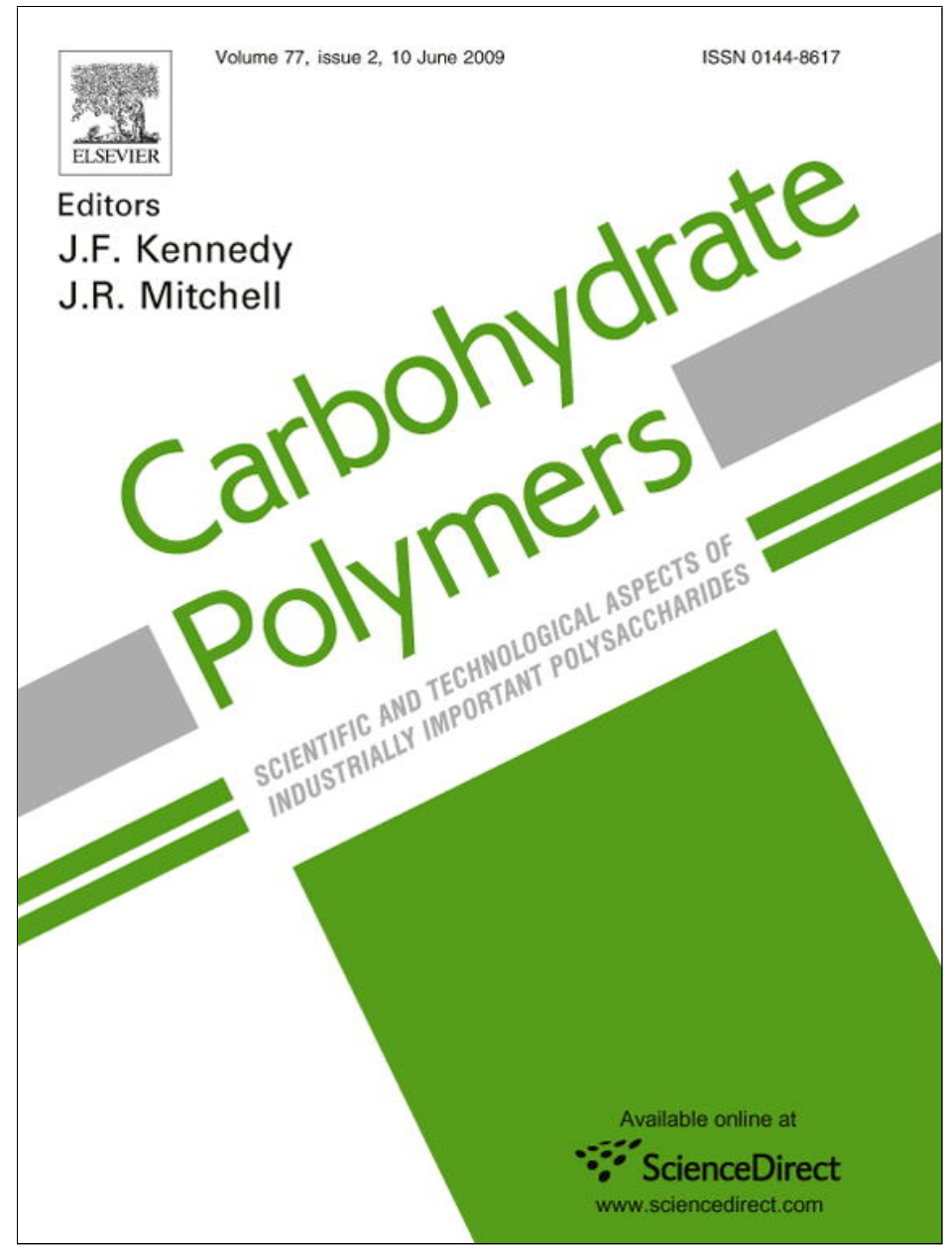

This article appeared in a journal published by Elsevier. The attached copy is furnished to the author for internal non-commercial research and education use, including for instruction at the authors institution and sharing with colleagues.

Other uses, including reproduction and distribution, or selling or licensing copies, or posting to personal, institutional or third party websites are prohibited.

In most cases authors are permitted to post their version of the article (e.g. in Word or Tex form) to their personal website or institutional repository. Authors requiring further information regarding Elsevier's archiving and manuscript policies are encouraged to visit:

http://www.elsevier.com/copyright 


\title{
Qualitative study of supramolecular assemblies of $\beta$-cyclodextrin and cholecalciferol and the cobalt (II), copper (II) and zinc (II) ions
}

\author{
Ana Lucia Ramalho Mercê ${ }^{\mathrm{a}}$, Jaqueline Nicolini ${ }^{\mathrm{a}}$, Mustayeen A. Khan ${ }^{\mathrm{b}}$, Gilles Bouet ${ }^{\mathrm{b}, *}$ \\ ${ }^{a}$ LEQ-UFPR, Departamento de Química, Centro Politécnico, CP 19081, CEP 81531-990 Curitiba-Pr, Brazil \\ ${ }^{\mathrm{b}}$ SONAS, EA 921, Faculté de Pharmacie, 16 Boulevard Daviers, $F$ - 49045 Angers Cedex 01, France
}

\section{A R T I C L E I N F O}

\section{Article history:}

Received 27 November 2008

Received in revised form 14 January 2009

Accepted 15 January 2009

Available online 30 January 2009

\section{Keywords:}

$\beta$-Cyclodextrin assemblies

${ }^{13} \mathrm{C}$ NMR

Diffuse reflectance

Vitamin D

Metal ions

\begin{abstract}
A B S T R A C T
$\mathrm{A}{ }^{13} \mathrm{C}$ NMR in DMSO- $\mathrm{d}_{6}$ as solvent, diffuse reflectance spectra and X-ray powder diagram study of the inclusion of vitamin $D$ in $\beta$-cyclodextrin and of the ternary assemblies with $\beta$-cyclodextrin, vitamin $D$ and metal ions (e.g. $\mathrm{Co}(\mathrm{II}), \mathrm{Cu}(\mathrm{II})$ and $\mathrm{Zn}(\mathrm{II})$ ) was carried out to determine the structure of these associations in which the molecular ratios ( $\beta$-cyclodextrin:vitamin D:metal ions) were 5:1:1 or 10:1:1.
\end{abstract}

(C) 2009 Elsevier Ltd. All rights reserved.

\section{Introduction}

Lipophilic vitamins (A, D, E and K) present very low solubility in water and consequently in biological media. Cyclodextrins, mainly $\beta$-cyclodextrins $(\beta-C D)$ are commonly used as inclusion material (Del Valle, 2004; Pitha, 1981). In fact, cyclodextrins are cyclic oligomers of $(1 \rightarrow 4)$ linked $\alpha$-D-glucose monomers and their main structural feature is their toroidal shape with an hydrophobic cavity (5-8 $\AA$ ) which can be used in chemical synthesis (Tabushi, Yamamura, Fujita, \& Kawakubo, 1979). In the case of $\beta-C D$ the size of this cavity is 6.0-6.5 $\AA$ for its diameter and the height is $7.9 \AA$ ( $\mathrm{Li}$ \& Purdy, 1992). In many cases, the inclusion complexes of vitamin $\mathrm{D}_{3}$ (VitD) or cholecalciferol do not take into account a third species like metal ion (Delaurent, Siouffi, \& Pepe, 1998; Tian \& Holick, 1995). Crespo-Biel et al. described a supramolecular complex with $\beta-\mathrm{CD}$ and metal-ion coordinated with ethylenediamine (CrespoBiel, Lim, Ravoo, Reinhoudt, \& Huskens, 2006) while Torri et al. described the complex inclusion of progesterone (Torri et al., 2007; Zoppetti et al., 2007). There are also papers dealing with metals derivatives inclusion but, as far as we know, without any organic molecule (Jiang et al., 2006, 2004; Matsui, Kurita, \& Date, 1972; Mochida \& Matsui, 1976). In addition, very few articles dealt with ternary complexes associating $\beta-\mathrm{CD}$, an organic molecule and a metal ion (Fernandes et al., 2006; Thanabal, Omecinsky, Reily, \& Cody, 1994; Zheng \& Tarr, 2006). The inclusion of metal complexes

\footnotetext{
* Corresponding author. Fax: +33241226600.

E-mail address: gilles.bouet@univ-angers.fr (G. Bouet).
}

of VitD should allow them to be more stable in aqueous media. We have previously determined the stability constants of various binary complexes of cholecalciferol (Mercê, Szpoganicz, Khan, Do Thanh, \& Bouet, 1999; Mercê et al., 1998; Mercê, Yano, Khan, Thanh, \& Bouet, 2003) and we describe in this paper supramolecular assemblies of $\beta$-cyclodextrin and cholecalciferol (VitD) and the cobalt (II), copper (II) and zinc (II) ions using ${ }^{13} \mathrm{C}$ NMR, diffuse reflectance UV-visible spectroscopy and X-ray powder diagrams.

\section{Experimental}

\subsection{Reagents}

$\beta$-Cyclodextrin (Aldrich, USA) and vitamin $\mathrm{D}_{3}$ or cholecalciferol (Sigma, USA) were analytical grade. Proper mass of the metal salts of $\mathrm{Cu}\left(\mathrm{NO}_{3}\right)_{2} \cdot 3 \mathrm{H}_{2} \mathrm{O}, \mathrm{CoCl}_{2} \cdot 6 \mathrm{H}_{2} \mathrm{O}$ (both p.a., Merck, Germany) and $\mathrm{ZnCl}_{2}$ (Janssen Chimica, Belgium) were used to make the initial aqueous solutions of the metal ions. The $\mathrm{pH}$ of copper (II) solutions were set with $0.1 \mathrm{~mol} \mathrm{~L}^{-1}$ aqueous solutions of either $\mathrm{HCl}$ or $\mathrm{KOH}$ p.a. (Merck, Germany) to 3.0 and 7.0, respectively.

\subsection{General technique of inclusion complexes}

In an Atmosbag ${ }^{\mathrm{TM}}$ (AL-211 - Aldrich) under dinitrogen atmosphere (Air Liquide, France) the reagents in water/ethanol solution $(50 \% \mathrm{v} / \mathrm{v})$ were mixed in a glass flask and let to react under magnetic stirring for $4 \mathrm{~h}$. The amounts were in all cases $0.200 \mathrm{mmol}$ of $\beta-C D, 0.02$ or $0.04 \mathrm{mmol}$ of cholecalciferol (VitD p.a, Sigma, 
USA) and finally 0.02 or $0.04 \mathrm{mmol}$ of metal ion depending on the ratio $\beta-C D: V i t D: \mathrm{M}^{2+}$, e.g.: $10: 1: 1$ or $5: 1: 1$, respectively. A small Schlenk glass flask capped with rubber stop (Saint-Gobain, Verneret, France) was used to weight the VitD outside the Atmosbag ${ }^{\mathrm{TM}}$. The solvent was completely removed under vacuum. The obtained solid was kept under $\mathrm{N}_{2}$ in a sealed small Schlenk glass flask.

\section{3. ${ }^{13}$ C NMR spectra}

The spectra were recorded at $20^{\circ} \mathrm{C}(293 \mathrm{~K})$. An amount of approximately $50 \mathrm{mg}$ of the samples were dissolved in $0.75 \mathrm{~mL}$ of DMSO- $\mathrm{d}_{6}\left(\mathrm{H}_{2} \mathrm{O}<0.02 \%\right.$, Eurisotop, France), and added with drops of 1,4-dioxane (99\%, Aldrich) as an internal standard. In our experimental conditions, the ${ }^{13} \mathrm{C}$ chemical shift of the singlet of 1,4-dioxane carbon atoms was $66.36 \mathrm{ppm}$ with respect to TMS (Jones, Katritzky, Murrell, \& Sheppard, 1962; Thanabal et al., 1994). This compound produces a singlet more accurate than the septuplet at c.a. $39.43 \mathrm{ppm}$ of DMSO- $\mathrm{d}_{6}$. Only ${ }^{13} \mathrm{C}$ spectra were recorded because most of metal complexes are paramagnetic species.

\subsection{Diffuse reflectance ultraviolet-visible spectroscopy}

An exact mass of $25-30 \mathrm{mg}$ of the solid samples were placed in an aluminum cell of $0.7 \mathrm{~cm}$ diameter and analyzed in a Shimadzu UV-2401PC spectrophotometer with an integration sphere (24052454-01). The absorbance from 190 to $900 \mathrm{~nm}$ and the reflectance from 0 to 100 were recorded for all samples.

\subsection{X-rays powder diagrams}

The X-rays powder diagrams were obtained using a Shimadzu $\mathrm{XD}$-3A diffractometer, with $\mathrm{Cu} \mathrm{K}_{\alpha}$ radiation with the samples in a glass holder.

\section{Results and discussion}

The proportions of the reagents were chosen in order to provide enough quantity of $\beta$-CD to encapsulate VitD. We have tested other $\beta$-CD-VitD ratios like 3:1, 2:1 and 1:1, respectively, but unsuccessful. The formation of the supramolecular structure was only observed when this ratio was at least 5:1. Finally, all experiments were performed using $5: 1$ or $10: 1 \beta-C D$ to VitD ratios for binary systems. Consequently, in the cases of ternary assemblies, the $\beta$ CD:VitD:metal ion ratios were $5: 1: 1$ or $10: 1: 1$. When mixing the three compounds without performing the above inclusion technique, no inclusion was observed. The variations of chemical shifts when passing from free components to inclusion complexes are very small because the interaction forces between host and guest molecules are only physical interactions like hydrogen bonding or Van der Waals electrostatic interactions.

\subsection{Vitamin $D$ and $\beta$-cyclodextrin ${ }^{13} C$ NMR spectra}

The carbon numbering scheme for cyclodextrin used in this paper was first proposed by French and Murphy(1973), Saenger et al. (1998) and Lipkowitz (1998). It is shown in Fig. 1b.

The ${ }^{13} \mathrm{C}$ NMR spectra of $\beta-C D$ in DMSO- $\mathrm{d}_{6}$ has been detailed by Jiang et al. (2007). The chemical shifts are $102.58 \mathrm{ppm}$ for $C(1)$; 72.80 for $\mathrm{C}(2)$; 73.80 for $\mathrm{C}(3)$; 81.55 for $\mathrm{C}(4)$; 72.53 for $\mathrm{C}(5)$ and finally $63.09 \mathrm{ppm}$ for $\mathrm{C}(6)$. Under our experimental conditions (Fig. 2), the chemical shifts are slightly modified: $101.889 \mathrm{C}(1)$; $72.370 \mathrm{C}(2) ; 73.010 \mathrm{C}(3) ; 81.490 \mathrm{C}(4) ; 72.000 \mathrm{C}(5)$ and $59.889 \mathrm{ppm} \mathrm{C}(6)$.

The ${ }^{13} \mathrm{C}$ NMR spectra of vitamin $\mathrm{D}$ in $\mathrm{CDCl}_{3}$ and of some of its analogues have been published by Berman, Luz, Mazur and Sheves

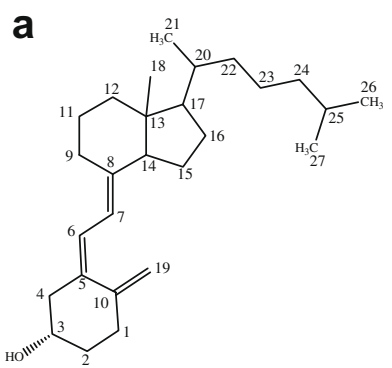

b

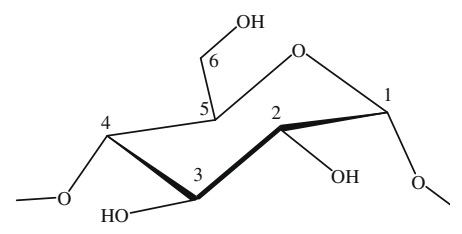

Fig. 1. Chemical structures of vitamin $D_{3}$ or cholecalciferol (a) and of one $\alpha$-Dglucose unit of $\beta-C D$, numbering scheme from Lipkowitz (1998) (b).

(1977) and in 1996 by Mizhiritskli,Konstantinovskii and Vishkautsan (1996) and are reported in Table 1. In our experimental conditions, the chemical shifts are slightly shifted (Fig. 2): e.g. $C_{\mathrm{v}}(1)$ at $32.197, \mathrm{C}_{\mathrm{v}}(2)$ at $35.481, \mathrm{C}_{\mathrm{v}}(3)$ at 67.904 and $C_{\mathrm{v}}(4)$ at $45.947 \mathrm{ppm}$ while $C_{\mathrm{v}}(11)$ appears at $21.871, C_{\mathrm{v}}(17)$ at 55.953 and $C_{\mathrm{v}}(18)$ at $11.833 \mathrm{ppm}$, respectively. As expected, the same small variations are observed for all other signals (Table 1 ).

\subsection{Binary assemblies ${ }^{13} \mathrm{C}$ NMR spectra}

The chemical shifts of ${ }^{13} \mathrm{C}$ signals of respectively, $\beta-\mathrm{CD}$ and VitD, are not coincidental. So, when $\beta-C D$ is only mixed with VitD, all signals referring to both compounds are present in the spectrum, while when they have undergone an inclusion reaction, all chemical shifts due to VitD are not present, as shown in Fig. 2. Only two peaks relative to VitD are observed for chemical shifts lower than $60 \mathrm{ppm}$. These signals correspond to the portion of VitD, which is outside the supramolecular structure (Jiang et al., 2007). The intracavity complexation of the substrate occurs only when the experimental conditions are used as described in Section 2.

In binary assemblies (Table 2), all signals relative to $\beta$-CD are slightly shifted $(+0.029$ to $0.045 \mathrm{ppm})$. In the mean time, the remaining signals relative to VitD are located at 18.632 and $55.994 \mathrm{ppm}$ corresponding to $\mathrm{C}(21)$ and $C(17)$, respectively. When the VitD is included in $\beta-C D$, no changes appear in the structure of the cyclodextrin. The hydrophilic moiety (e.g. C(3) with $\mathrm{OH}$ ) of the cholecalciferol is inside the cavity, while only two lipophilic carbons produce a signal and are located at the outside part of the $\beta-C D$ cavity. The inner carbon atoms of the $\beta-C D$ molecules (e.g. $C_{\mathrm{v}}(1)$ to $\left.C_{\mathrm{v}}(4)\right)$ could lead to hydrogen bonding with the hydroxyl of the VitD.

\subsection{Ternary complexes ${ }^{13} \mathrm{C}$ NMR spectra}

\subsubsection{Cobalt complexes}

The ${ }^{13} \mathrm{C}$ NMR spectra are given Fig. 3 and the main chemical shifts are reported in Table 3 . In binary assemblies with cobalt (II) in both studied ratios (Fig. 3a and b) very few changes are observed in the spectrum of $\beta-\mathrm{CD}$. A small new signal appeared at c.a. $31 \mathrm{ppm}$, higher for 5:1 ratio than for 10:1 ratio. In ternary inclusion complexes, this new signal remains and some additional signals from VitD are observed at 18.60 and 56.05 for 5:1:1 ratio and $30.74 \mathrm{ppm}$ for 10:1:1 ratio. The other signals corresponding to VitD (not shown on Fig. 3) are located as follows: $C_{\mathrm{v}}(5)$ at $144 \mathrm{ppm}$, $C_{\mathrm{v}}(11)$ and $C_{\mathrm{v}}(26)$ at 22.4 and $22.7 \mathrm{ppm}$, respectively, for $\beta-\mathrm{CD}-$ VitD-Co assembled in 10:1:1 ratio (Fig. 3d). So, in this complex, the alkyl moiety of VitD is outside the cavity.

The metal ion complexes have probably twisted the bonds around $C_{\mathrm{v}}(5)$ and $C_{\mathrm{v}}(8)$ in order to fit all rings and alkyl portions inside the cavity of $\beta$-CD. To obtain such a space for the whole molecule of VitD, an ion channel structure (Saenger et al., 1998) is 


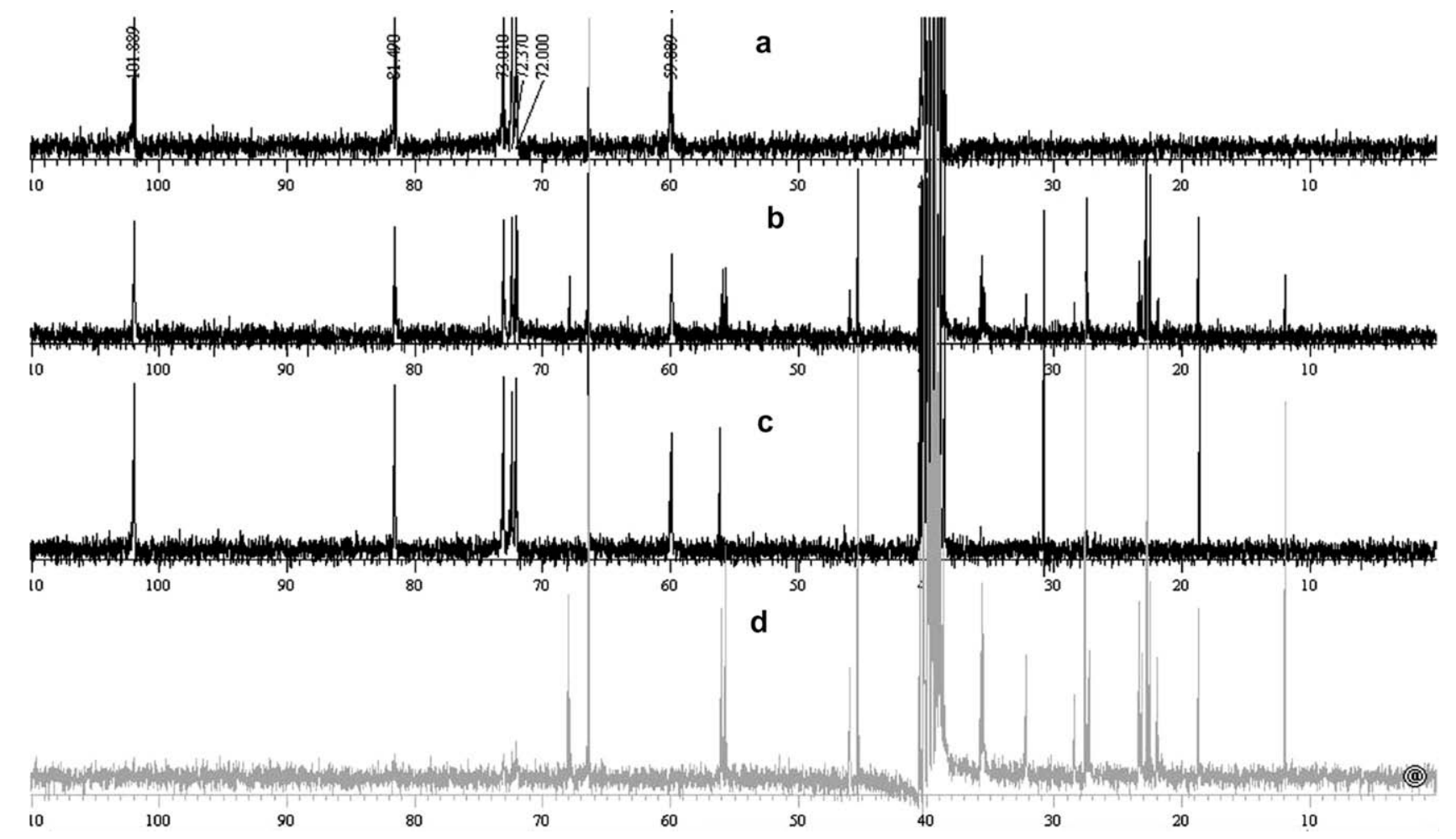

Fig. 2. ${ }^{13} \mathrm{C}$ NMR spectra: (a) $\beta-C D$; (b) mixture $\beta-C D+V i t D_{3}$; (c) reaction between $\beta-C D$ and VitD; (d) VitD alone.

Table 1

Chemical shifts $\left({ }^{13} \mathrm{C}, \mathrm{ppm}\right)$ of vitamin $\mathrm{D}_{3}$.

\begin{tabular}{lrrr}
\hline$C_{\mathrm{v}}{ }^{\mathrm{a}}$ & Ref. (Mizhiritskli et al., 1996) & Ref. (Berman et al., 1977) & This work \\
\hline 1 & 32.55 & 32.05 & 32.197 \\
2 & 35.78 & 35.25 & 35.481 \\
3 & 69.83 & 69.20 & 67.904 \\
4 & 46.55 & 46.00 & 45.947 \\
5 & 135.69 & 145.20 & 145.387 \\
6 & 123.10 & 122.40 & 120.964 \\
7 & 118.13 & 117.65 & 117.434 \\
8 & 142.90 & 142.10 & 140.553 \\
9 & 29.65 & 29.10 & 28.376 \\
10 & 145.70 & 135.25 & 145.395 \\
11 & 24.21 & 22.30 & 21.871 \\
12 & 41.04 & 40.65 & 39.955 \\
13 & 46.41 & 45.90 & 45.262 \\
14 & 57.06 & 56.40 & 55.621 \\
15 & 22.87 & 23.60 & 22.418 \\
16 & 28.43 & 27.70 & 27.463 \\
17 & 57.08 & 56.75 & 55.953 \\
18 & 12.91 & 12.05 & 11.833 \\
19 & 113.06 & 112.35 & 111.797 \\
20 & 41.04 & & 40.447 \\
21 & 18.23 & & 18.671 \\
22 & 136.25 & & \\
23 & 135.28 & & \\
24 & 43.45 & & 35.401 \\
25 & 34.74 & & \\
26 & 20.29 & & \\
27 & 20.60 & & \\
28 & 21.75 & & \\
\hline a v 5 vbscript means C atoms from VitD & & \\
& & &
\end{tabular}

${ }^{a} \mathrm{v}$ Subscript means $\mathrm{C}$ atoms from VitD.

probably being formed with cobalt (II) in the 5:1:1 ratio. On the other hand, when cobalt (II) is in the equilibrium in 10:1:1 $\beta$ $\mathrm{CD}+\mathrm{VitD}+$ Co ratio complex, the probably spatial arrangement is herringbone or back-type structures, as $C_{\mathrm{v}}(17)$ till $C_{\mathrm{v}}(26)$ atoms show ${ }^{13} \mathrm{C}$ NMR signals in the supramolecular formed structure.
Table 2

Chemical shifts $\left({ }^{13} \mathrm{C}\right.$, DMSO- $\mathrm{d}_{6}$, dioxane as internal reference, $\left.\mathrm{ppm}\right)$ of $\beta-\mathrm{CD}$ and in binary complex.

\begin{tabular}{lrrrrrr}
\hline Compound & \multicolumn{1}{l}{$C(1)$} & \multicolumn{1}{l}{$C(2)$} & \multicolumn{1}{l}{$C(3)$} & \multicolumn{1}{l}{$C(4)$} & \multicolumn{1}{l}{$C(5)$} & \multicolumn{1}{l}{$\mathrm{C}(6)$} \\
\hline$\beta-\mathrm{CD}$ & 101.873 & 72.355 & 72.994 & 81.475 & 71.985 & 59.874 \\
$\beta-\mathrm{CD}+$ VitD & 101.918 & 72.397 & 73.029 & 81.507 & 72.014 & 59.905 \\
$\Delta \delta$ & 0.045 & 0.042 & 0.035 & 0.032 & 0.029 & 0.031 \\
\hline
\end{tabular}

The signals relative to $\beta$-CD are shifted to smaller values (Table 3 ) and the difference is greater in the case of binary complexes with cobalt (II) ions. Some complexes with VitD and cobalt ions have been previously described (Gadais, Khan, Bouet, \& Thanh, 1994). In these species, the coordination occurs through the hydroxyl on $\mathrm{C}(1)$. As the $\mathrm{Co}^{\mathrm{II}}$ cation stands in an octahedral geometry, the internal hydroxyl functions from $\beta$-CD may be involved in the structure of the ternary complexes as indicated by the signal of $C(1)$ in all spectrum, whatever the complex.

\subsubsection{Copper complexes}

The ${ }^{13} \mathrm{C}$ NMR spectra for copper derivatives are given Figs. 4 and 5 and the main chemical shifts are reported in Table 4 . In binary assemblies with copper (II), in both studied ratios, very few changes are observed in the spectrum of $\beta-C D$. A weak singlet appeared at $30.72 \mathrm{ppm}$ for 10:1 ratio $(\mathrm{pH} 7)$ but there is no new signal for $\mathrm{pH} 3$ (Fig. 4a and b). In ternary inclusion complexes obtained in the 5:1:1 ratio at $\mathrm{pH} 3$ and $\mathrm{pH}$ 7, only the signals due to $\beta$-CD are present.

In binary complexes (Fig. 4), only positive shifts are observed for all the signals (Table 4). In the cases of the ternary assemblies obtained at $\mathrm{pH} 3$, the signal corresponding to $\mathrm{C}(2)$ is shifted to higher values whatever the ratio of reactants. The most important downfield shift is observed for $\mathrm{C}(5)$ at $\mathrm{pH} 7$, with a $5: 1: 1$ ratio. On the opposite side, the shift is identical for this carbon for both ratios. The inner $C(2)$, bearing an hydroxyl functional group is in- 


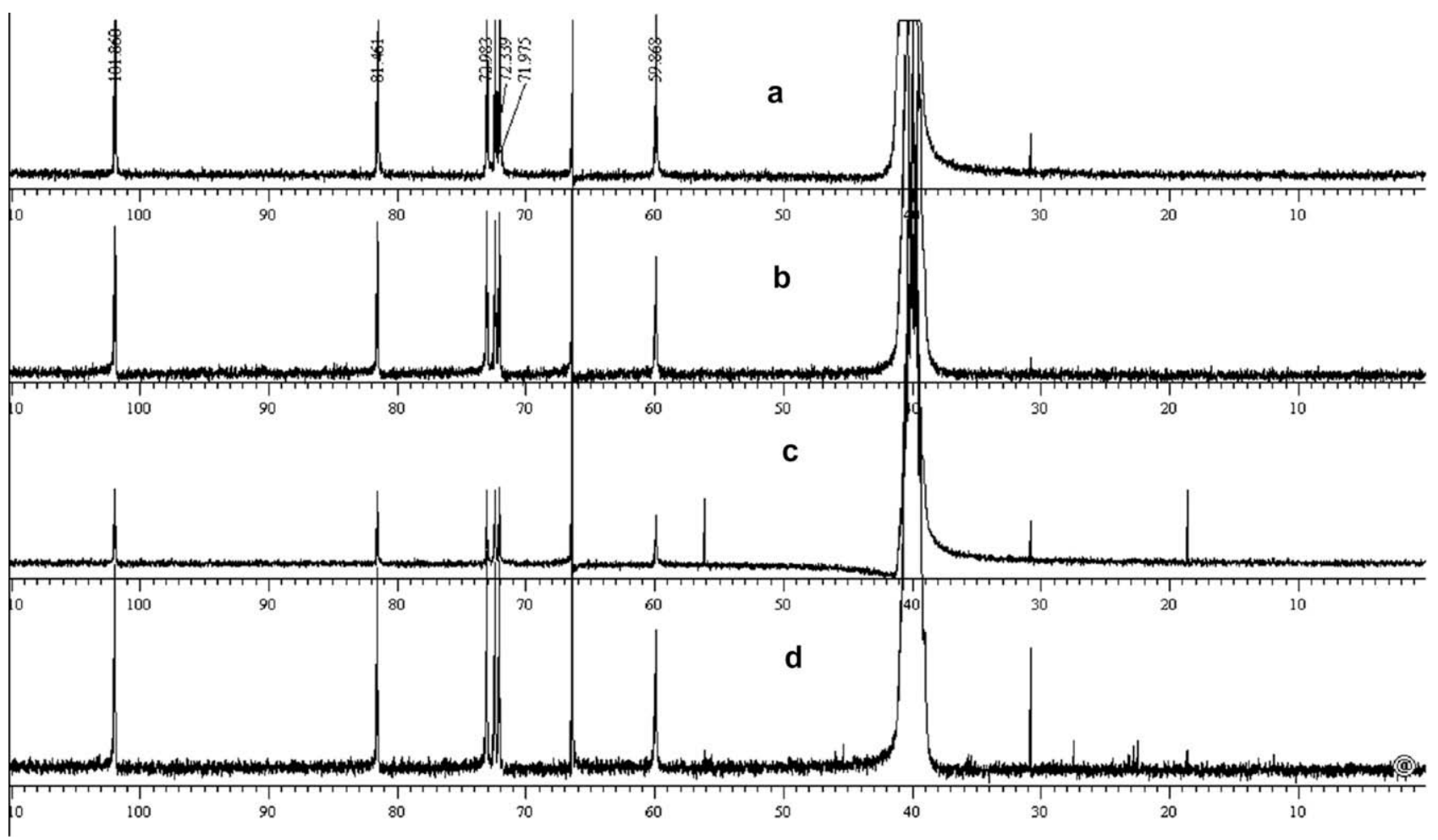

Fig. 3. ${ }^{13} \mathrm{C}$ NMR at $\mathrm{pH} 7$. (a) $\beta-\mathrm{CD}+\mathrm{Co}^{2+}, 5: 1$; (b) $\beta-\mathrm{CD}+\mathrm{Co}^{2+}, 10: 1$; (c) $\beta-\mathrm{CD}+\mathrm{VitD}+\mathrm{Co}^{2+}, 5: 1: 1$; (d) $\beta-\mathrm{CD}+\mathrm{VitD}+\mathrm{Co}{ }^{2+}, 10: 1: 1$.

Table 3

Chemical shifts in ppm $\left({ }^{13} \mathrm{C}\right.$, DMSO-d6, dioxane as internal reference) of $\beta$-CD complexes in the supramolecular assemblies with cobalt ions. $\Delta \delta$ means the mathematical differences among the chemical shifts of $\beta-C D$ alone and the chemical shifts for the supramolecular assembly.

\begin{tabular}{|c|c|c|c|c|c|c|c|}
\hline Complex & Ratio & $C(1)$ & $C(2)$ & $C(3)$ & $C(4)$ & $C(5)$ & $C(6)$ \\
\hline$\beta-\mathrm{CD}+\mathrm{Co}^{2+}$ & $5: 1$ & 101.860 & 71.975 & 72.983 & 81.461 & 72.339 & 59.868 \\
\hline$\Delta \delta-\beta-C D$ & & -0.058 & -0.039 & -0.046 & -0.046 & -0.058 & -0.037 \\
\hline$\beta-\mathrm{CD}+\mathrm{Co}^{2+}$ & 10:1 & 101.868 & 71.987 & 72.999 & 81.476 & 72.358 & 59.872 \\
\hline$\Delta \delta-\beta-C D$ & & -0.050 & -0.027 & -0.030 & -0.031 & -0.039 & -0.033 \\
\hline$\beta-C D+V i t D+C^{2+}$ & $5: 1: 1$ & 101.888 & 72.000 & 72.997 & 81.472 & 72.367 & 59.875 \\
\hline$\Delta \delta-\beta-C D+V i t D$ & & -0.030 & -0.014 & -0.032 & -0.035 & -0.030 & -0.030 \\
\hline$\beta-C D+V i t D+C^{2+}$ & $10: 1: 1$ & 101.900 & 72.016 & 73.014 & 81.504 & 72.366 & 59.887 \\
\hline$\Delta \delta-\beta-C D+V i t D$ & & -0.018 & 0.002 & -0.015 & -0.003 & -0.031 & -0.018 \\
\hline
\end{tabular}

volved in the chelation of the copper ion together with VitD, inside the cavity of the $\beta-C D$.

According to the Irving-Williams series, the copper (II) complexes are more stable than cobalt (II) complexes (Irving \& Williams, 1953; Mercê et al., 2003). So, the copper ions (binary species) may coordinate with inner $\mathrm{OH}$ groups of $\beta-\mathrm{CD}$ and therefore no changes could be seen in the spectra. In the case of the ternary assemblies, the copper (II) ions are linked to VitD inside the $\beta$ CD cavity.

\subsubsection{Zinc complexes}

The corresponding spectra ( $\mathrm{pH} \mathrm{7)}$ are given in Fig. 6 and the main chemical shifts are reported in Table 5 . In the binary assemblies, a new signal at 30.73 is present with a feeble intensity in the case of 10:1 ratio and with a high intensity for 5:1 ratio.

In the spectra of the ternary assemblies, there is not any signal from VitD carbon atoms and the spectra are quite identical to those obtained in the case of copper assemblies. So, the structure of these ternary assemblies look like those obtained with copper (II) ions.

\subsection{Diffuse reflectance spectra}

In the diffuse reflectance and UV-visible results, the maximum absorption bands are reported in Table 6 for each solid supramolecular structure obtained from the three metal ions studied. Although the accuracy in reading the maximum wavelength is not the same than with samples in aqueous solutions, it can be seen that the differences among the absorptions due to charge transfer transitions and $\mathrm{d}-\mathrm{d}$ transitions bands are enough to show that different products were obtained with $\beta-C D$ and the three studied metal ions in the absence and in the presence of VitD.

The bands appear in the same region than in the case of the spectra of various solutions of cobalt (II) species (Fine, 1962; Lechat, Khan, Bouet, \& Vierling, 1993). For instance, when $\mathrm{Co}^{2+}$ ion was complexed to $\beta-C D$, the maximum absorption wavelengths were 210 and $205 \mathrm{~nm}$ in the ultraviolet region and 527 and $536 \mathrm{~nm}(\mathrm{~d}-\mathrm{d})$, for 10:1 and 5:1 $\beta$-CD-Co ratios, respectively. These bands are located at 208 and $529 \mathrm{~nm}(\mathrm{~d}-\mathrm{d})$ for both ratios, for the same metal ion in the presence of the supramolecular structure, 


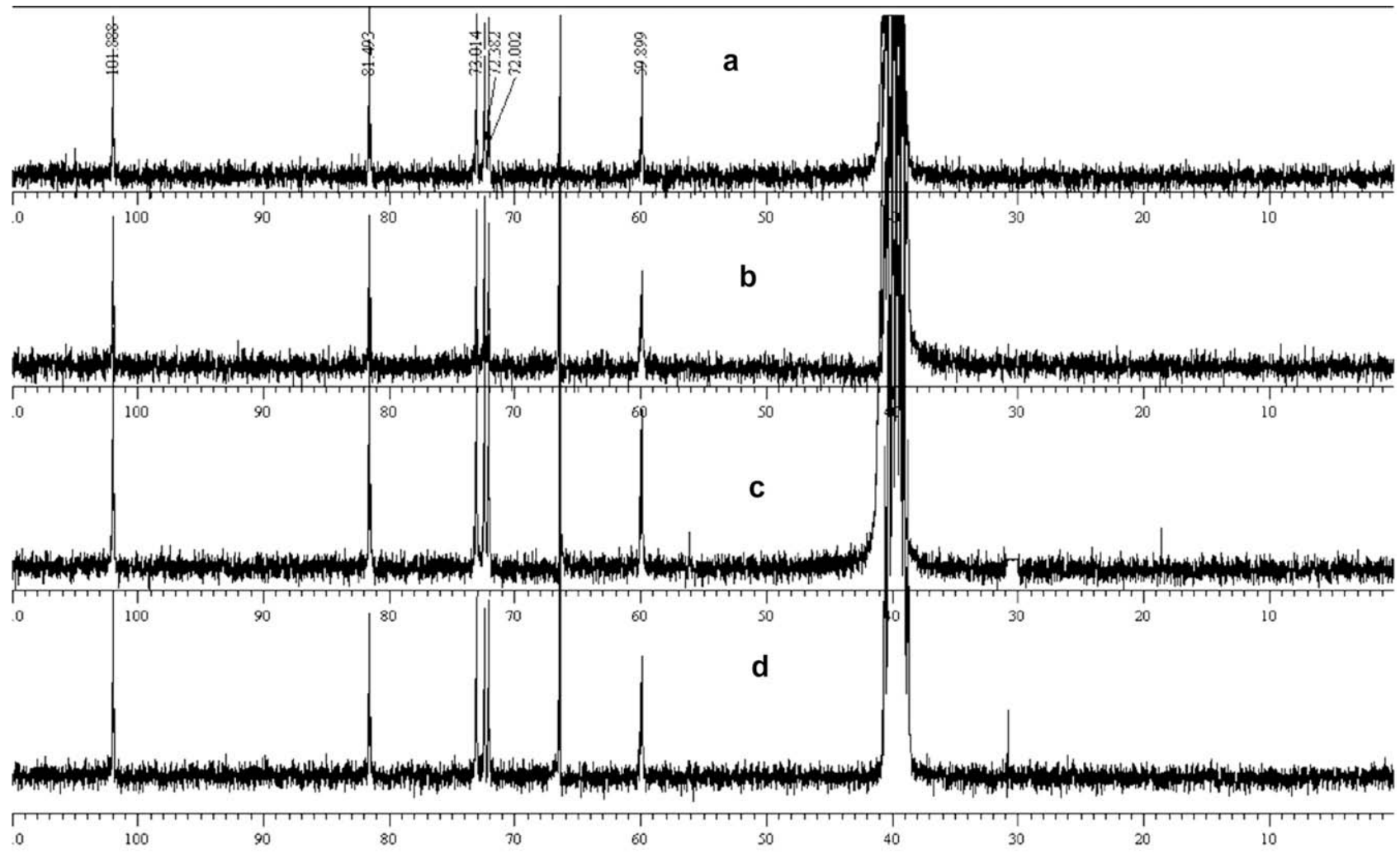

Fig. 4. (a) ${ }^{13} \mathrm{C}$ NMR of $\beta-C D+\mathrm{Cu}^{2+}$ 5:1 L:M, pH 3; (b) $\beta-C D+\mathrm{Cu}^{2+} 10: 1 \mathrm{~L}: \mathrm{M}, \mathrm{pH} 3$; (c) $\beta-\mathrm{CD}+\mathrm{Cu}^{2+}$ 5:1 L:M, pH 7; (d) $\beta-\mathrm{CD}+\mathrm{Cu}{ }^{2+} 10: 1 \mathrm{~L}: \mathrm{M}, \mathrm{pH} 7$.

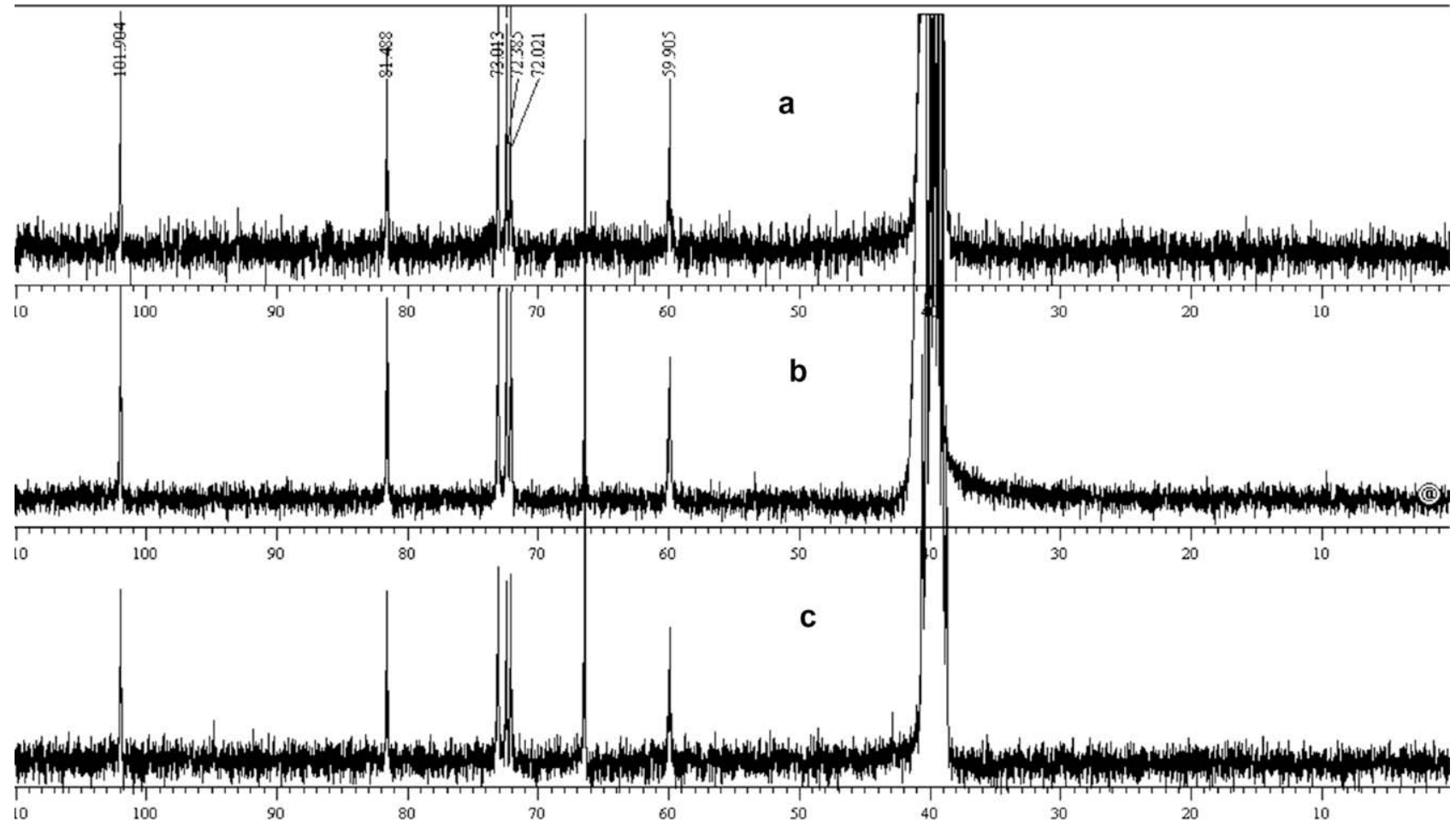

Fig. 5. (a) ${ }^{13} \mathrm{C}$ NMR of $\beta-C D+V i t D+\mathrm{Cu}^{2+} 5: 1: 1, \mathrm{pH} 3$; (b) $\beta-C D+V i t D+\mathrm{Cu}^{2+} 5: 1: 1, \mathrm{pH} 7$; (c) $\beta-C D+V i t D+C u^{2+} 10: 1: 1$, pH 3 .

$\beta$-CD-VitD. Although the spectra are not well resolved due to the amorphous and not very homogeneous character of the obtained complexes, the differences in the wavelengths are enough to show that the supramolecular assembly was forming different complexes than $\beta-C D$ alone and the same metal ion. The same kind of difference was observed in the systems $\beta-C D$ and the supramo- 
Table 4

Chemical shifts in ppm $\left({ }^{13} \mathrm{C}\right.$, DMSO- $\mathrm{d}_{6}$, dioxane as internal reference) of $\beta$-CD complexes in the supramolecular ternary complexes with copper ions. $\Delta \delta$ means the mathematical differences among the chemical shifts of $\beta-C D$ alone and the chemical shifts for the supramolecular assembly.

\begin{tabular}{|c|c|c|c|c|c|c|c|c|}
\hline Complex & Ratio & $\mathrm{pH}$ & $C(1)$ & $C(2)$ & $C(3)$ & $C(4)$ & $C(5)$ & $C(6)$ \\
\hline$\beta-\mathrm{CD}+\mathrm{Cu}^{2+}$ & $5: 1$ & 3 & 101.888 & 72.002 & 73.014 & 81.493 & 72.382 & 59.899 \\
\hline$\Delta \delta-\beta-C D$ & & & 0.015 & 0.017 & 0.020 & 0.018 & 0.027 & 0.025 \\
\hline$\beta-C D+\mathrm{Cu}^{2+}$ & $10: 1$ & 3 & 101.887 & 71.999 & 73.008 & 81.491 & 72.373 & 59.875 \\
\hline$\Delta \delta-\beta-C D$ & & & 0.014 & 0.014 & 0.014 & 0.016 & 0.018 & 0.001 \\
\hline$\beta-C D+\mathrm{Cu}^{2+}$ & $5: 1$ & 7 & 101.904 & 72.018 & 73.027 & 81.508 & 72.384 & 59.902 \\
\hline$\Delta \delta-\beta-\mathrm{CD}$ & & & 0.031 & 0.033 & 0.033 & 0.033 & 0.029 & 0.028 \\
\hline$\beta-C D+\mathrm{Cu}^{2+}$ & $10: 1$ & 7 & 101.904 & 72.019 & 73.012 & 81.504 & 72.382 & 59.889 \\
\hline$\Delta \delta-\beta-\mathrm{CD}$ & & & 0.031 & 0.034 & 0.018 & 0.029 & 0.027 & 0.015 \\
\hline$\beta-C D+V i t D+C^{2+}$ & $5: 1$ & 3 & 101.904 & 72.021 & 73.013 & 81.488 & 72.385 & 59.905 \\
\hline$\Delta \delta-\beta-C D+V i t D$ & & & -0.014 & 0.007 & -0.016 & -0.019 & -0.012 & 0 \\
\hline$\beta-C D+V i t D+C^{2+}$ & $5: 1: 1$ & 7 & 101.885 & 72.000 & 73.013 & 81.491 & 72.354 & 59.901 \\
\hline$\Delta \delta-\beta-C D+V i t D$ & & & -0.033 & -0.014 & -0.016 & -0.016 & -0.043 & -0.004 \\
\hline$\beta-C D+V i t D+C^{2+}$ & $10: 1: 1$ & 3 & 101.885 & 72.017 & 73.013 & 81.492 & 72.385 & 59.887 \\
\hline$\Delta \delta-\beta-\mathrm{CD}+\mathrm{VitD}$ & & & -0.033 & 0.003 & -0.016 & -0.015 & -0.012 & -0.018 \\
\hline
\end{tabular}

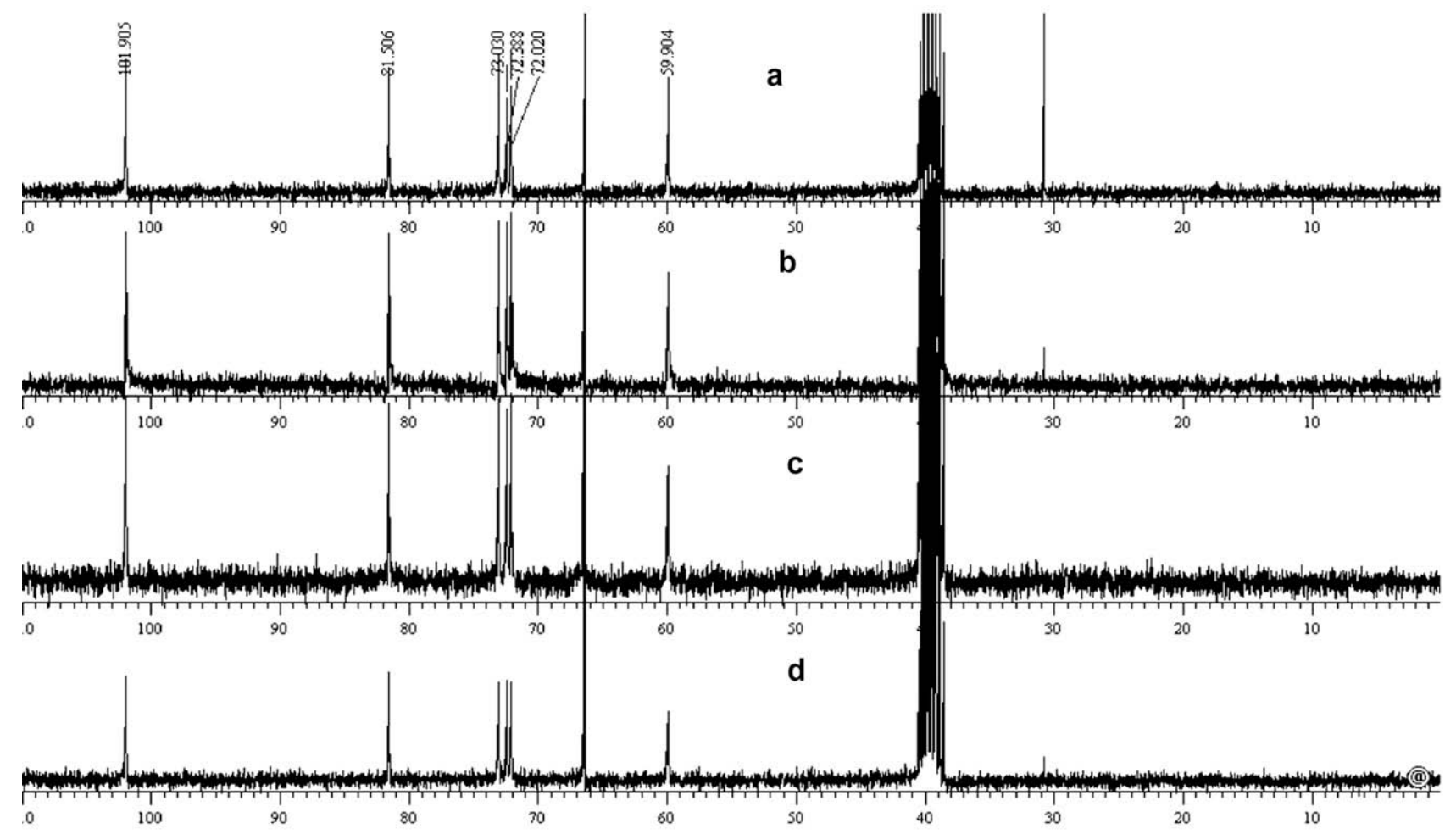

Fig. 6. (a) ${ }^{13} \mathrm{C}$ NMR of $\beta-C D+Z n^{2+} 5: 1 \mathrm{~L}: \mathrm{M}, \mathrm{pH} 7$; (b) $\beta-C D+\mathrm{Zn}^{2+} 10: 1 \mathrm{~L}: \mathrm{M}, \mathrm{pH} 7$; (c) $\beta-\mathrm{CD}+\mathrm{VitD}+\mathrm{Zn}{ }^{2+} 5: 1 \mathrm{~L}: \mathrm{M}, \mathrm{pH} 7$; (d) $\beta-\mathrm{CD}+\mathrm{VitD}+\mathrm{Zn}{ }^{2+} 10: 1 \mathrm{~L}: \mathrm{M}, \mathrm{pH} 7$.

Table 5

Chemical shifts in ppm $\left({ }^{13} \mathrm{C}\right.$, DMSO- $\mathrm{d}_{6}$, dioxane as internal reference) of $\beta$-CD complexes in the supramolecular ternary complexes with zinc ions. $\Delta \delta$ means the mathematical differences among the chemical shifts of $\beta-C D$ alone and the chemical shifts for the supramolecular assembly.

\begin{tabular}{|c|c|c|c|c|c|c|c|}
\hline Complex & Ratio & $C(1)$ & $C(2)$ & $C(3)$ & $C(4)$ & $C(5)$ & $C(6)$ \\
\hline$\beta-C D+Z n^{2+}$ & $5: 1$ & 101.905 & 72.020 & 73.03 & 81.506 & 72.388 & 59.904 \\
\hline$\Delta \delta-\beta-C D$ & & -0.013 & 0.006 & 0.001 & -0.001 & -0.009 & -0.001 \\
\hline$\beta-C D+Z^{2+}$ & $10: 1$ & 101.888 & 72.017 & 73.014 & 81.494 & 72.371 & 59.887 \\
\hline$\Delta \delta-\beta-C D$ & & -0.030 & 0.003 & -0.015 & -0.013 & -0.026 & -0.018 \\
\hline$\beta-C D+V i t D+Z^{2+}$ & $5: 1: 1$ & 101.901 & 72.021 & 73.03 & 81.509 & 72.386 & 59.905 \\
\hline$\Delta \delta-\beta-C D+V i t D$ & & -0.017 & 0.007 & 0.001 & 0.002 & -0.011 & 0 \\
\hline$\beta-C D+V i t D+Z^{2+}$ & $10: 1: 1$ & 101.902 & 72.017 & 73.026 & 81.509 & 72.388 & 59.905 \\
\hline$\Delta \delta-\beta-C D+V i t D$ & & -0.016 & 0.003 & -0.003 & 0.002 & -0.009 & 0 \\
\hline
\end{tabular}

lecular $\beta$-CD-VitD and the other two metal ions e.g. $\mathrm{Cu}^{\mathrm{II}}$ and $\mathrm{Zn}^{\mathrm{II}}$ (not shown in Fig. 7).

Another interesting feature was the complex $\beta$-CD-VitD-Co 10:1:1 ratio be a pink solid, showing that $\mathrm{Co}^{2+}$ is a six coordinate complex with also water as ligand. The diffuse reflectance and UV-visible spectrum showed transitions in the visible region very similar to all cobalt (II) complexes that presented themselves as blue solids (Fig. 7). However, all visible transitions seem to have 
Table 6

Maximum absorptions (nm) for diffuse reflectance ultraviolet-visible spectroscopy for the solid samples of $\beta$-CD, VitD, binary and ternary assemblies.

\begin{tabular}{llll}
\hline Compound & UV-max 1 & UV-max 2 & d-d Transitions \\
\hline$\beta-C D$ & $214 \pm 1$ & - & - \\
VitD alone & - & $328 \pm 1$ & - \\
$\beta-C D+V i t D$ & $216 \pm 4$ & $260 \pm 4$ & - \\
$\beta-C D+\mathrm{Co}^{2+} 5: 1$ & $205 \pm 3$ & - & $536 \pm 3$ \\
$\beta-C D+\mathrm{Co}^{2+} 10: 1$ & $210 \pm 1$ & - & $527 \pm 3$ \\
$\beta-C D+V i t D+\mathrm{Co}^{2+} 5: 1: 1$ & $208 \pm 4$ & $269 \pm 4$ & $529 \pm 2$ \\
& & & $628 \pm 0$ \\
$\beta-C D+V i t D+\mathrm{Co}^{2+} 10: 1: 1$ & $208 \pm 0$ & $260 \pm 2$ & $600 \pm 0$ \\
$\beta-C D+\mathrm{Cu}^{2+}+5: 1 \mathrm{pH} 3$ & $210 \pm 0$ & $278 \pm 0$ & $548 \pm 1$ \\
$\beta-C D+\mathrm{Cu}^{2+}+10: 1 \mathrm{pH} 3$ & $212 \pm 3$ & $273 \pm 6$ & $557 \pm 4$ \\
$\beta-C D+\mathrm{Cu}^{2+}+5: 1 \mathrm{pH} 7$ & $212 \pm 0$ & $264 \pm 2$ & $423 \pm 6$ \\
$\beta-C D+\mathrm{Cu}^{2+}+10: 1 \mathrm{pH} 7$ & $212 \pm 0$ & $264 \pm 2$ & $483 \pm 4$ \\
$\beta-C D+V i t D+\mathrm{Cu}^{2+}-5: 1: 1 \mathrm{pH} 3$ & $216 \pm 2$ & $268 \pm 2$ & $548 \pm 9$ \\
$\beta-C D+V i t D-\mathrm{Cu}^{2+}-5: 1: 1 \mathrm{pH} 7$ & $207 \pm 0$ & $264 \pm 0$ & $530 \pm 0$ \\
$\beta-C D+V i t D+\mathrm{Cu}^{2+}-10: 1: 1 \mathrm{pH} 3$ & $207 \pm 3$ & $266 \pm 3$ & $570 \pm 2$ \\
$\beta-C D+V i t D+\mathrm{Cu}^{2+}-10: 1: 1 \mathrm{pH} 7$ & $207 \pm 0$ & $264 \pm 0$ & $530 \pm 0$ \\
$\beta-C D+\mathrm{Zn}^{2+} 5: 1$ & $212 \pm 0$ & - & - \\
$\beta-C D+\mathrm{Zn}^{2+} 10: 1$ & $207 \pm 4$ & - & - \\
$\beta-C D+V i t D+\mathrm{Zn}^{2+} 5: 1: 1$ & $210 \pm 9$ & $257 \pm 3$ & - \\
$\beta-C D+V i t D+\mathrm{Zn}^{2+} 10: 1: 1$ & $211 \pm 2$ & $260 \pm 1$ & - \\
\hline
\end{tabular}

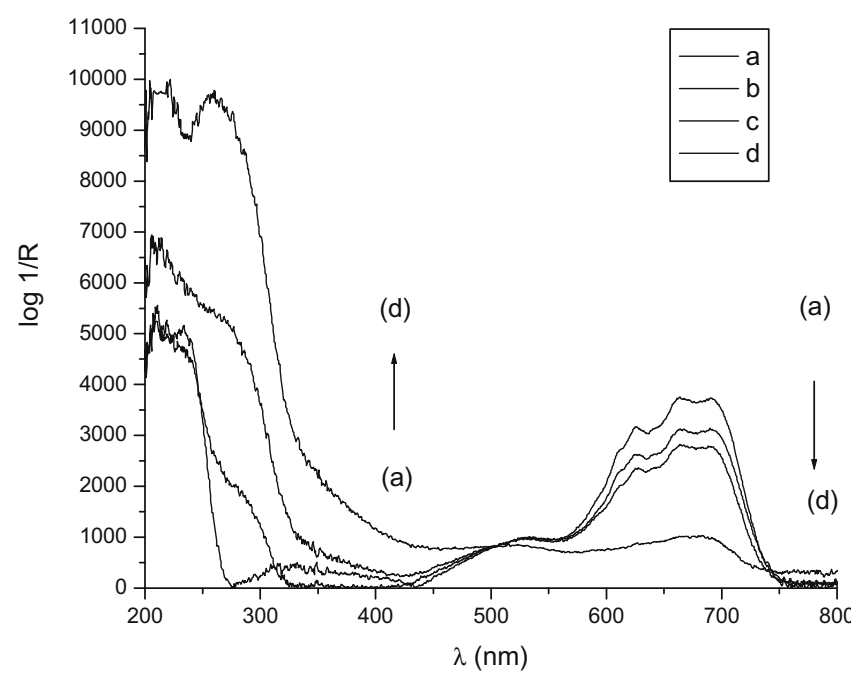

Fig. 7. Diffuse reflectance UV-vis of the samples containing cobalt (II): (a) $\beta$ $\mathrm{CD}+\mathrm{Co}^{2+}, \quad 5: 1$; (b) $\beta-\mathrm{CD}+\mathrm{Co}^{2+}, \quad 10: 1$; (c) $\beta-\mathrm{CD}+\mathrm{VitD}+\mathrm{Co}^{2+}, 5: 1: 1 ;$ (d) $\beta-$ $\mathrm{CD}+\mathrm{VitD}+\mathrm{Co}^{2+}, 10: 1: 1$

disappeared in the pink complex (Fig. 7d). These visible transitions $(625,660$ and $690 \mathrm{~nm})$ are compatible with a four coordinate trigonal bipyramidal structure, and at $530 \mathrm{~nm}$, the diffuse reflectance signal is derived from an octahedral structure (Lever, 1984). So the $\beta$-CD-VitD-Co (10:1:1 ratio) complexes presented almost only octahedral structure in the obtained complexes. On the other hand, the blue solids presented a great majority of trigonal bipyramidal structure. This feature, once again, showed the importance of the ratio between $\beta-C D$ and VitD in the experimental step in order to obtain the inclusion compound (refer to Fig. 7d).

\subsection{X-ray diffraction}

Powder X-ray diffraction patterns afford information about the type of the cyclodextrin: cage, layer or channel type (Okumura, Kawaguchi, \& Harada, 2001). The four diffraction patterns of ternary complexes given in Fig. 8 are close to those described for $\beta$ CD cage structure (Jiao, Goh, Valiyaveettil, \& Zheng, 2003), with main peaks at $c a .2 \theta=10.8^{\circ}, 12.5^{\circ}, 15.7^{\circ}$ and $19.2^{\circ}$. It is has been

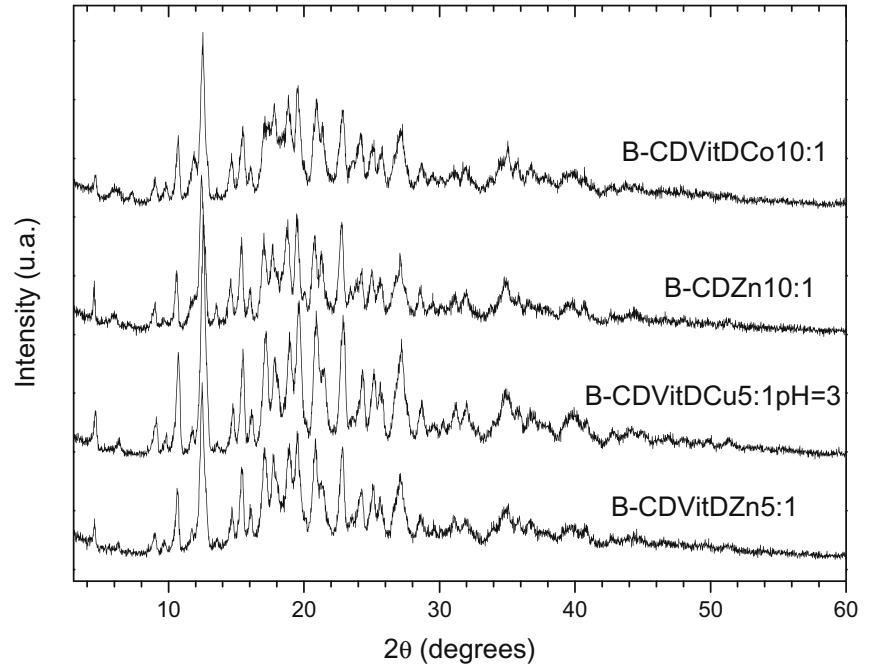

Fig. 8. X-ray diffraction spectra of complexes of $\beta-C D$ and VitD and metal ions.

shown that, in the case of $\beta$-CD inclusion complexes, the cyclodextrin turned into channel type and the number of diffraction peaks is lower than with pure $\beta-C D$ (Jiao et al., 2003; Li \& Yan, 2001; YanAn et al., 2005). These results show that the crystallinity of $\beta$-cyclodextrin is the same no matter if it is alone in aqueous solutions, complexed to the metal ions $\mathrm{Co}^{2+}, \mathrm{Cu}^{2+}$ and $\mathrm{Zn}^{2+}$ or when in the supramolecular assembly with VitD and complexed with the studied metal ions.

These results also show that the arrangement of pure $\beta-C D$ (Saenger et al., 1998), is not maintained in the supramolecular structure formed in this work.

\section{Conclusion}

We have synthesized new ternary assemblies gathering $\beta$ cyclodextrin, vitamin $\mathrm{D}_{3}$ (cholecalciferol) and three metal ions: $\mathrm{Co}(\mathrm{II}), \mathrm{Cu}(\mathrm{II})$ and $\mathrm{Zn}(\mathrm{II})$. Using ${ }^{13} \mathrm{C}$ NMR, UV-visible diffuse reflectance spectroscopy and powder X-ray diffraction pattern, we have shown that VitD gives metal complexes with these three metal and these complexes are included in the inner cavity of $\beta-C D$. These ternary assemblies could only be observed in our experimental conditions when the ratio $\beta-\mathrm{CD}$ :VitD:metal ion was $10: 1: 1$ or $5: 1: 1$ at $\mathrm{pH}$ 3 as well as $\mathrm{pH} 7$.

\section{References}

Berman, E., Luz, Z., Mazur, Y., \& Sheves, M. (1977). Conformational analysis of vitamin D and analogs. 1. Carbon-13 and proton nuclear magnetic resonance study. Journal of Organic Chemistry, 42, 3325-3330.

Crespo-Biel, O., Lim, C. W., Ravoo, B. J., Reinhoudt, D. N., \& Huskens, J. (2006). Expression of a supramolecular complex at a multivalent interface. Journal of the American Chemical Society, 128, 17024-17032.

Del Valle, E. M. M. (2004). Cyclodextrins and their uses: A review. Process Biochemistry, 39, 1033-1046.

Delaurent, C., Siouffi, A. M., \& Pepe, G. (1998). Cyclodextrin inclusion complexes with vitamin D3: Investigations of the solid complex characterization. Chemia Analityczna, 43, 601-616.

Fernandes, J. A., Braga, S. S., Pillinger, M., Sa Ferreira, R. A., Carlos, L. D., Hazell, A. et al. (2006). $\beta$-Cyclodextrin inclusion of europium(III) tris([beta]-diketonate)bipyridine. Polyhedron, 25, 1471-1476.

Fine, D. A. (1962). Halide complexes of cobalt(II) in acetone solution. Journal of the American Chemical Society, 84, 1139-1144.

French, A. D., \& Murphy, V. G. (1973). The effects of changes in ring geometry on computer models of amylose. Carbohydrate Research, 27, 391-406.

Gadais, J. F., Khan, M. A., Bouet, G. M., \& Thanh, X. D. (1994). Spectroscopic evidence for cobalt(II) complexes with 25-hydroxycholecalciferol and $1 \alpha, 25-$ dihydroxycholecalciferol in aqueous solution. Transition Metal Chemistry, 19, 651-652.

Irving, H., \& Williams, R. J. P. (1953). The stability of transition-metal complexes. Journal of Chemical Society, 3192. 
Jiang, H., Sun, H., Zhang, S., Hua, R., Xu, Y., Jin, S., et al. (2007). NMR investigations of inclusion complexes between $\beta$-cyclodextrin and naphthalene/anthraquinone derivatives. Journal of Inclusion Phenomena and Macrocyclic Chemistry, 58, 133-138.

Jiang, Y., Du, L., Lu, F., Li, Z., Yang, J., Bie, S., et al. (2006). Synthesis and properties of functionalized beta-cyclodextrin copolymer and its metal complexes. Polymer Bulletin, 57, 481-489.

Jiang, Y., Zhang, H., Li, H., Wu, M., Zhang, S., \& Wang, J. (2004). Studies on novel functional $\beta$-cyclodextrin and its metal complexes. Journal of Molecular Structure, 702, 33-37.

Jiao, H., Goh, S. H., Valiyaveettil, S., \& Zheng, J. (2003). Inclusion complexes of perfluorinated oligomers with cyclodextrins. Macromolecules, 36, 4241-4243.

Jones, R. A. Y., Katritzky, A. R., Murrell, J. N., \& Sheppard, N. (1962). Internal refrerence standards for proton magnetic resonance in aqueous solutions. Journal of Chemical Society, 2576-2578.

Lechat, S., Khan, M. A., Bouet, G., \& Vierling, F. (1993). Spectrophotometric study of cobalt(II) chloride complexes in ethanol and propan-2-ol. Inorganica Chimica Acta, 211, 33-36.

Lever, A. B. P. (1984). Inorganic electronic spectroscopy. Amsterdam: Elsevier.

Li, J., \& Yan, D. (2001). Inclusion complexes formation between cyclodextrins and poly(1, 3-dioxolane). Macromolecules, 34, 1542-1544.

Li, S., \& Purdy, W. C. (1992). Cyclodextrins and their applications in analytical chemistry. Chemical Reviews, 92, 1457-1470.

Lipkowitz, K. B. (1998). Applications of computational chemistry to the study of cyclodextrins. Chemical Reviews, 98, 1829-1874.

Matsui, Y., Kurita, T., \& Date, Y. (1972). Complexes of copper(II) with cyclodextrins. Bulletin of the Chemical Society of Japan, 45, 3229.

Mercê, A. L. R., Szpoganicz, B., Khan, M. A., Do Thanh, X., \& Bouet, G. (1999). Potentiometric study of vitamin D3 complexes with manganese(II), iron(II), iron(III) and zinc(II) in water-ethanol medium. Journal of Inorganic Biochemistry, 73, 167-172

Mercê, A. L. R., Szpoganicz, B., Dutra, R. C., Khan, M. A., Do Thanh, X., \& Bouet, G. (1998). Potentiometric study of vitamin D3 complexes with cobalt (II), nickel (II) and copper (II) in water-ethanol medium. Journal of Inorganic Biochemistry, 71, 87-91.

Mercê, A. L. R., Yano, L. S., Khan, M. A., Thanh, X. D., \& Bouet, G. (2003). Complexing power of vitamin $\mathrm{D}_{3}$ toward various metals. Potentiometric studies of vitamin $\mathrm{D}_{3}$ complexes with $\mathrm{Al}^{3+}, \mathrm{Cd}^{2+}, \mathrm{Gd}^{3+}$, and $\mathrm{Pb}^{2+}$ ions in water ethanol solution. Journal of Solution Chemistry, 32, 1075-1085.
Mizhiritskli, M. D., Konstantinovskii, L. E., \& Vishkautsan, R. (1996). 2D NMR study of solution conformations and complete ${ }^{1} \mathrm{H}$ and ${ }^{13} \mathrm{C}$ chemical shifts assignments of vitamin D metabolites and analogs. Tetrahedron, 52, 1239-1252.

Mochida, K., \& Matsui, Y. (1976). Kinetic study of the formation of a binuclear complex between copper(II) and cyclodextrin. Chemistry Letters, 963-966.

Okumura, H., Kawaguchi, Y., \& Harada, A. (2001). Preparation and characterization of inclusion complexes of poly(dimethylsiloxane)s with cyclodextrins. Macromolecules, 34, 6338-6343.

Pitha, J. (1981). Enhanced water solubility of vitamins A, D, E, and K by substituted cycloamyloses. Life Sciences, 29, 307-311.

Saenger, W., Jacob, J., Gessler, K., Steiner, T., Hoffmann, D., Sanbe, H., et al. (1998). Structures of the common cyclodextrins and their larger analogues-beyond the doughnut. Chemical Reviews, 98, 1787-1802.

Tabushi, I., Yamamura, K., Fujita, K., \& Kawakubo, H. (1979). Specific inclusion catalysis by $\beta$-cyclodextrin in the one-step preparation of vitamin $\mathrm{K} 1$ or $\mathrm{K} 2$ analogues. Journal of the American Chemical Society, 101, 1019-1026.

Thanabal, V., Omecinsky, D. O., Reily, M. D., \& Cody, W. L. (1994). The 13C chemical shifts of amino acids in aqueous solution containing organic solvents: Application to the secondary structure characterization of peptides in aqueous trifluoroethanol solution. Journal of Biomolecular NMR, 4, 47-59.

Tian, X. Q., \& Holick, M. F. (1995). Catalyzed thermal isomerization between previtamin $D_{3}$ and vitamin $D_{3}$ via $\beta$-cyclodextrin complexation. Journal of Biological Chemistry, 270, 8706-8711.

Torri, G., Bertini, S., Giavana, T., Guerrini, M., Puppini, N., \& Zoppetti, G. (2007). Inclusion complex characterization between progesterone and hydroxypropyl$\beta$-cyclodextrin in aqueous solution by NMR study. Journal of Inclusion Phenomena and Macrocyclic Chemistry, 57, 317-321.

Yan-An, G., Zhong-Hao, L., Ji-Min, D., Bu-Xing, H., Gan-Zuo, L., Wan-Guo, H., et al. (2005). Preparation and characterization of inclusion complexes of $\beta$ cyclodextrin with ionic liquid. Chemistry - A European Journal, 11, 5875-5880.

Zheng, W., \& Tarr, M. A. (2006). Assessment of ternary iron-cyclodextrin-2-naphthol complexes using NMR and fluorescence spectroscopies. Spectrochimica Acta A, 65, 1098-1103.

Zoppetti, G., Puppini, N., Pizzutti, M., Fini, A., Giovani, T., \& Comini, S. (2007). Water soluble progesterone-hydroxypropyl- $\beta$-cyclodextrin complex for injectable formulations. Journal of Inclusion Phenomena and Macrocyclic Chemistry, 57, 283-288. 